\title{
Composition and Application of Aircraft Towing Tractor Automatic Control System
}

\author{
Liu Tianchang ${ }^{1,2}$ \\ ${ }^{1}$ School of Electronic Information and Electrical Engineering, Shanghai Jiaotong University, Shanghai, China \\ ${ }^{2}$ Flight Test Center, Commercial Aircraft Corporation of China, Ltd., Shanghai, China
}

\section{Email address:}

tianchangsjtu@outlook.com

\section{To cite this article:}

Liu Tianchang. Composition and Application of Aircraft Towing Tractor Automatic Control System. Engineering and Applied Sciences. Vol. 4, No. 6, 2019, pp. 190-195. doi: 10.11648/j.eas.20190406.17

Received: November 20, 2019; Accepted: December 9, 2019; Published: December 18, 2019

\begin{abstract}
The airports construction level is improved and the construction scale is constantly expanded with the rapid development of society, economy and science and technology, which brings a good development prospect for aircraft towing tractors. On the basis of summarizing the current research and application of aircraft towing tractors, the traction characteristics of towbar and towbarless aircraft tractors were analyzed, and the mechanical, electric, hydrodynamic and hydraulic transmission automatic control system were compared. The composition, working principle and application of hydraulic steering control system, hydraulic braking control system, hydraulic clamping and lifting mechanism and hydraulic hybrid power system of aircraft towing tractors were emphatically discussed. The results show that the configuration of towbarless traction is flexible and the traction capability is strong. Hydraulically controlled aircraft towing tractor has good traction, braking and control characteristics. Electronic hydraulic braking system is precisely controllable, and the hydraulic hybrid technology is beneficial to reduce the energy consumption of aircraft towing tractors. The demand for aircraft towing tractors is increasing with the expansion of the airport distribution and construction, on the basis of constantly improving the existing aircraft towing tractor and according to the needs of airport operation, it is necessary to adopt innovative technology to develop energy-saving, environment-friendly and intelligent aircraft towing tractors, so as to adapt the development needs of aviation industry.
\end{abstract}

Keywords: Aircraft Towing Tractor, Automatic Control System, Intelligent Vehicle, Special Vehicle

\section{Introduction}

Aircraft towing tractor is a kind of special airfield ground vehicle used for pulling or pushing aircrafts. Its transmission control system includes mechanical, electric, hydrodynamic and hydraulic transmission. The mechanical transmission was used in early aircraft towing tractors, but it has been rarely used because of its poor flexibility and other shortcomings. Electric power transmission is mainly used in small and medium-sized aircraft towing tractors due to the influence of transmission power and the battery life. Hydraulic transmission is main used in the aircraft towing tractors [1-3], it is connected by flexible pipe, it has flexible structure and a wider range of stepless speed regulation, better dynamic braking characteristics, superior to the ability of overload protection and a continuous transformation output [4-5].

Lufthansa and Krauss Maffei manufactured the world's first towbarless aircraft tractor in the early 1980s. So far, the more famous are Douglas company in UK, GHH company in Germany, TLD company in France, FMC company in the United States, IAI company in Israel and so on. Some manufacturers in China have begun to produce aircraft tractors since 1990s. At present, some Chinese enterprises in Beijing, Qingdao, shenzhen, shenyang, weihai and other places can produce small and medium-sized aircraft towing tractors.

According to the application of aircraft towing tractor, the characteristics of towbar and towbarless aircraft tractor were discussed. The main transmission modes of aircraft towing tractor were compared and analyzed, and on this basis, hydraulic steering control system, hydraulic braking control system, hydraulic clamping lifting mechanism and hydraulic hybrid power control system of aircraft towing tractor were discussed in detail. 


\section{Traction and Transmission Control Modes of Aircraft Towing Tractor}

\subsection{Traction Modes}

According to the connection between aircraft and aircraft towing tractor, the traction mode of aircraft towing tractor can be divided into towbar and towbarless traction. Towbar traction has been applied in civil aviation airports for a long time. The aircraft and the tractor are connected by the traction bar to control the movement of the aircraft under the push or pull action of the traction bar. The traction bar has torsion shear and buffer device, which can transfer traction force and reduce the impact between the tractor and the aircraft. The towbarless tractor cancels the traction rod and uses its clamping lifting device to directly connect with the landing gear of the aircraft. At present, it has developed rapidly and has become the main traction of the aircraft towing tractor [6-8]. The relationship between the aircraft towing tractor and the aircraft is shown in figure 1.

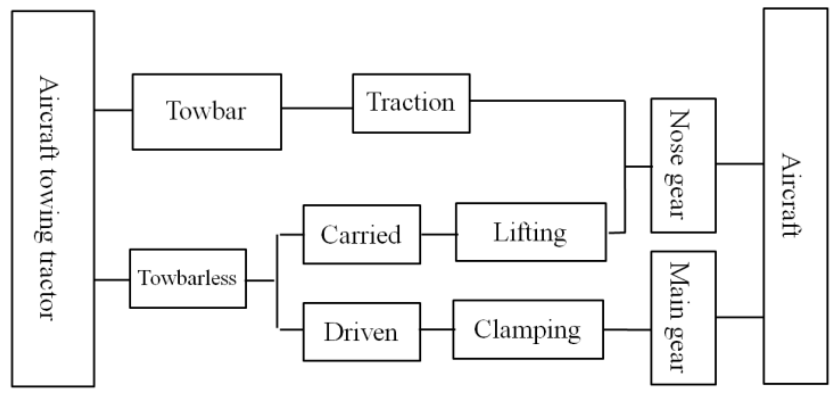

Figure 1. Relationship between aircraft towing tractor and aircraft.

By comparing the interaction between the aircraft towing tractor and the aircraft, the characteristics of towbar and towbarless traction are shown in table 1 .

Table 1. Characteristics of towbar and towbarless traction.

\begin{tabular}{|c|c|c|}
\hline Type of traction & Advantage & Disadvantage \\
\hline Towbar & $\begin{array}{l}\text { (1) Structure, control and drive are simple and flexible, low } \\
\text { production cost. (2) The tractor is not directly contacted with the } \\
\text { aircraft, so it is not necessary to consider the adaptability of the } \\
\text { connection device. The aircraft can be pulled as long as there is a } \\
\text { corresponding traction bar and appropriate traction force. (3) It } \\
\text { can be used to pull aircrafts and also be used to carry other } \\
\text { equipments through the connection of the traction bar. }\end{array}$ & $\begin{array}{l}\text { (1) In the traction process, the turning radius is large and the } \\
\text { traction speed is low. The installation and disassembly of the } \\
\text { traction towbar need a specially-assigned person, the operation } \\
\text { is complex and the working efficiency is low. (2) Different } \\
\text { types of aircraft should generally be equipped with different } \\
\text { traction towbars. The application scope is limited. (3) The } \\
\text { tractor is heavy and the energy consumption is high. }\end{array}$ \\
\hline
\end{tabular}

From the development trend, towbarless traction will become the main form of aircraft towing tractor. The main characteristic of the towbarless aircraft tractor is that hydraulic drive is used and the main power source is the internal combustion engine, it can meet the needs of multi-type aircraft traction. In order to meet the comprehensive guarantee of various working conditions, aircraft tractor will develop towards the direction of high efficiency, energy saving, emission reduction and intelligence. In the future, aircraft tractor can be designed into highly integrated intelligent products such as machine, electricity, liquid and gas through intelligent vehicle technology [9]. In addition, the aircraft is automatically towed to the corridor bridge by an unmanned aircraft tractor after landing through unmanned driving technology [10], and it can be directly sent to the runway by an unmanned vehicle when the aircraft leaves the tarmac, which can save a lot of fuel, improve the utilization rate of the vehicle, and reduce energy consumption. With the continuous expansion of airport construction scale, it has a broad prospect to develop a new generation of aircraft tractor combined with the intelligent automobile and unmanned driving technology.

\subsection{Transmission Control System}

There are four main transmission control system for aircraft towing tractor, i.e. mechanical, electric, hydrodynamic and hydraulic. Mechanical transmission has been rarely used due to the impact of shifting, large parts, cumbersome and other reasons. Because some key parts of electric transmission have not reached the practical degree, it is mainly used in small tractors, and will be applied to medium tractors in the future. Hydraulic transmission is gradually becoming the mainstream transmission mode of the large and medium-sized aircraft towing tractors due to the wider infinitely variable speed range, better power braking characteristics, superior overload protection and the ability to continuously transform the output power [11-12]. The characteristics of the four transmission control systems are shown in table 2 .

Table 2. The characteristics of aircraft towing tractor transmission control system.

\begin{tabular}{lll}
\hline Transmission control system & Advantage & Disadvantage \\
\hline \multirow{2}{*}{ Mechanical control system } & $\begin{array}{l}\text { (1) Simple structure, mature technology, less } \\
\text { precision parts, lower price. Maintenance and repair }\end{array}$ & $\begin{array}{l}\text { (1) Gear transmission has shifting impact, starting is not } \\
\text { gentle, it is adverse to smooth traction. Shifting is }\end{array}$ \\
\hline
\end{tabular}




\begin{tabular}{|c|c|c|}
\hline Transmission control system & Advantage & Disadvantage \\
\hline & $\begin{array}{l}\text { is easy. (2) High transmission efficiency, the change } \\
\text { of output speed with the load is small. The failure rate } \\
\text { is low, and the requirements for operation conditions } \\
\text { are not strict. (3) The match with the engine is strict, } \\
\text { and the engine can be used to brake in a certain speed } \\
\text { range. }\end{array}$ & $\begin{array}{l}\text { accompanied by power interruption, so the efficiency is low } \\
\text { for vehicles with frequent shifting. (2) A longer pull rod is } \\
\text { usually used, overall layout is limited, and the scheduling is } \\
\text { not flexible, operation is cumbersome. It is difficult to realize } \\
\text { remote control and automatic control. (3) The load varies } \\
\text { greatly, it is easy to cause a sudden change in engine speed. } \\
\text { The engine is easy to stall when overload is running. }\end{array}$ \\
\hline Electric control system & $\begin{array}{l}\text { (1) The motor and generator are connected by flexible } \\
\text { cable, which is more convenient than hydraulic pipe. } \\
\text { The association degree with microelectronic } \\
\text { technology is high, and it is easy to achieve automatic } \\
\text { control and remote control. (2) Stable engine } \\
\text { operation, low fuel consumption, small pollution and } \\
\text { long life. (3) Easy to realize internal combustion } \\
\text { engine and battery hybrid mode drive. }\end{array}$ & $\begin{array}{l}\text { (1) Power density is small, it is mainly used for small } \\
\text { towbarless tractors. (2) The motor is large and heavy, the } \\
\text { structure is very cumbersome and complicated. ( } 3 \text { ) Nonferrous } \\
\text { metals and other special materials are consumed more than } \\
\text { others, the price is higher. (4) It is difficult to solve the } \\
\text { problems of anti-jamming and electromagnetic compatibility. }\end{array}$ \\
\hline Hydrodynamic control system & $\begin{array}{l}\text { (1) The output speed and torque can be maintained } \\
\text { within a certain range. The output torque can be } \\
\text { automatically increased when the load increases. (2) } \\
\text { Automatic gearbox is equipped, operation conditions } \\
\text { are significantly better than mechanical transmission. } \\
\text { (3) The shifting number of times is obviously less } \\
\text { than the mechanical transmission, and the invalid } \\
\text { time of power interruption is shortened. (4) The } \\
\text { torque converter can absorb the impact load, avoid } \\
\text { the overload, and extend the working life of the } \\
\text { engine. }\end{array}$ & $\begin{array}{l}\text { (1) The torque of hydraulic converter is small, and the sudden } \\
\text { change of gearbox transmission ratio still exists. The matching } \\
\text { between torque converter and engine are very demanding, the } \\
\text { versatility is poor. The structure is more complicated than the } \\
\text { mechanical transmission and the cost is higher. (2) The } \\
\text { maximum output torque can only be obtained when the engine } \\
\text { speed is the highest, but the efficiency is very low when the } \\
\text { engine speed is low and the torque is high, which is not } \\
\text { conducive to energy saving, emission and noise reduction. (3) } \\
\text { The power braking ability is poor, the driving brake works } \\
\text { frequently and wears quickly. (4) It is difficult to arrange the } \\
\text { structure in the towbarless tractors with four-wheel drive. }\end{array}$ \\
\hline Hydraulic control system & $\begin{array}{l}\text { (1) The input and output components are connected } \\
\text { by flexible pipes. Starting, speed regulation and } \\
\text { reversing are soft and fast, the micro feature is } \\
\text { excellent. (2) The traction force and the speed } \\
\text { adjustment characteristics are good, the vehicle can } \\
\text { produce high output torque in low speed. The engine } \\
\text { can run in stable and efficient conditions, which is } \\
\text { beneficial to energy saving, emission reduction and } \\
\text { engine life extension. (3) Controllable braking can be } \\
\text { achieved by power transmission from maximum } \\
\text { speed to full rest. The braking torque is equivalent to } \\
\text { the driving torque, which is less likely to cause wear } \\
\text { of the components. }\end{array}$ & $\begin{array}{l}\text { (1) Precision components, high manufacturing technology, } \\
\text { high cost. (2) Steady-state transmission efficiency is low, } \\
\text { which is not suitable for long distance stable driving vehicles. } \\
\text { (3) The maintenance is more complex, and the maintenance } \\
\text { technical level is high. }\end{array}$ \\
\hline
\end{tabular}

\section{Hydraulic Transmission Control System of Aircraft Towing Tractor}

\subsection{Hydraulic Steering Control System}

The steering control system of aircraft towing tractor includes front wheel steering, four-wheel centripetal steering and four-wheel crab steering. Steering system is mainly composed of steering pump, steering device, electromagnetic reversing valve, constant flow valve, hydraulic control one-way valve and steering cylinder. In order to keep the steering oil pipe is filled with oil, hydraulic control one-way valve is used to guarantee the synchronous movement of steering wheel. The front and rear wheels can be returned to the center position through the resetting device to ensure the correct driving direction of the vehicle [13].

According to the front and rear axle steering cylinder connection, hydraulic steering system can be divided into series and parallel. The series form mainly consists of hydraulic pump, steering device, front axle steering cylinder, rear axle control valve group and rear axle steering cylinder. The rear wheel steering responds faster because the oil in the front axle steering cylinder does not return to the hydraulic tank but directly reaches the rear axle steering cylinder. However, the series steering may have the problem of lag of the rear wheel steering due to the leakage of hydraulic components in different degrees. The parallel circuit is mainly composed of hydraulic pump, steering device, steering mode control valve group, two-way overload valve group, front axle steering cylinder and rear axle steering cylinder. When the steering control system works, the hydraulic oil flows through the steering mode control valve group, and then flows to the front axle steering oil cylinder and the rear axle steering oil cylinder independently through the shunt valve. The return oil circuit of the front axle steering oil cylinder is directly connected to the oil tank and relatively independent [14-15].

\subsection{Hydraulic Brake Control System}

The hydraulic braking control system of aircraft towing tractor is mainly composed of hydraulic pump, one-way 
valve, electromagnetic reversing valve, pressure switch, accumulator, manual pump, hand brake valve, foot brake valve, shuttle valve and relay valve. The brake safety can be guaranteed by double circuit brake valve. The two spool valves in the double circuit brake valve are mechanically connected and protected by two accumulators. When braking is completed, the oil returns to the tank through the brake and relay valve. If one of the braking circuits fails, the second can continue to operate to ensure braking safety.

With the development of automobile intelligence, the traditional brake system can not meet the requirements of the vehicle control system. Line control technology has developed rapidly, such as automatic emergency braking system and advanced driving assistance system. Line control system can be divided into electromechanical braking system and electronic hydraulic braking system. Electronic hydraulic braking system is an important development direction of the automobile braking system, its main characteristic is to replace some mechanical parts in traditional braking system with electronic components. Electronic hydraulic braking system retains the original mature and reliable hydraulic parts, with the advantages of compact structure, rapid response, accurately controlled braking force, and it is easy to achieve a variety of active safety control functions. Many well-known vehicle and parts companies, such as German Bosch, Continental LSP, Daimler Chrysler, American TRW, Delphi, Japanese Hitachi, Honda, Toyota, Korean Mando, etc., have put forward the electronic hydraulic braking system scheme and its hydraulic pressure control method, and carried out simulation and experimental research [16]. Tsinghua university, Jilin university, Tongji university, Nanjing university of aeronautics and astronautics, Wuhan university of technology, Jiangsu university and others in China have carried out simulation or bench test research on the electronic hydraulic braking control system [17].

The main factors affecting the energy consumption characteristics of electronic hydraulic braking control system include braking intensity, the maximum and minimum working pressure, air pressure of accumulator, accumulator effective displacement and brake wheel cylinder piston diameter. The energy consumption of electronic hydraulic braking system is affected by the strength of braking and braking wheel cylinder piston diameter. Reducing the maximum working pressure of the system and the piston diameter of the braking wheel cylinder is beneficial to reducing the power consumption of the electronic hydraulic braking system. The change of the minimum working pressure of the system and the effective displacement of the accumulator has little influence on the energy consumption of the electronic hydraulic braking system. Increasing the charging pressure of the accumulator, reducing the effective displacement of the accumulator and reducing the piston diameter of the brake wheel cylinder are beneficial to reducing the volume of the accumulator.

\subsection{Hydraulic Clamping and Lifting Mechanism}

Clamping lifting mechanism can be divided into clamping mechanism and lifting mechanism. It is the part directly connected with the towbarless aircraft tractor, and it is also the key mechanism of the towbarless aircraft tractors. Clamping mechanism includes four forms, i.e. rotary clamping type, symmetric orbital type, asymmetric orbital type and orbital spring type. Symmetric orbital type and rotary clamping type are more commonly used [18]. German Goldhofer company produces special ground equipments for airports, its towbarless tractor mainly includes AST-1 and AST-3 series, AST-1 adopts symmetrical rotary clamping mechanism and AST-3 adopts symmetrical track clamping mechanism.

The clamping lifting mechanism of towbarless aircraft tractor is mainly composed of clamping mechanism, bearing lifting platform, hinge head, hydraulic cylinder and other components. When the aircraft is docked with towbarless tractor, the aircraft landing gear enters the clamping lifting device of the tractor by the hydraulic cylinder lifting action. The front wheel of the aircraft is completely fixed with the lifting platform by the hydraulic clamping device, and is clamped and lifted to a certain height by the lifting device which is driven by the lift hydraulic cylinder.

In order to adapt the using of A380, Douglas began to develop the TBL-600 aircraft towing tractor in 2005, its clamping mechanism adopts the single-side rotary clamping. The German SPACER series hydraulic system provides constant pressure support to the left and right wheels of the front landing gear, this configuration serves as a safety protection for the nose landing gear. With the improvement of the automation of the towbarless aircraft tractor, Schopf has developed a semi-automatic aircraft tractor, the driving clamping mechanism is adopted. During the process of clamping and traction, the aircraft wheel always keeps contact with the ground and rolls. Guangtai company has proposed a new type of towbarless tractor, which can restrain the front landing gear wheel at least three points at the same time when clamping the aircraft front landing gear, thus improving the safety of traction.

\subsection{Hydraulic Hybrid Control System}

Hybrid electric vehicles can recover energy and store it during braking, and the energy is released during starting and accelerating, thus achieve the purpose of energy recovery and reuse [19-20]. This is the energy saving mechanism of hydraulic hybrid system [21-22], when the tractor needs to brake or slow down, the secondary element (hydraulic pump/motor) works in the state of hydraulic pump, the braking energy of the tractor is stored in the hydraulic accumulator in the form of high pressure hydraulic oil by compressing the gas in the accumulator, the vehicle's kinetic energy is converted to the form of hydraulic energy stored in the accumulator. When the tractor starts up again and accelerates, the accumulator releases energy, and the hydraulic oil flow through the secondary components to drive the tractor, the energy is converted from the form of hydraulic energy to the kinetic energy, thus reducing the engine fuel consumption. 
Compared with electric hybrid vehicles, hydraulic hybrid vehicles overcome the problems of low energy recovery and battery affected by temperature, it has the advantages of long life, high reliability, easy maintenance, simple structure, high power density, flexible layout and so on. More and more attention is being paid to hydraulic hybrid vehicles with the development of vehicles towards energy saving and emission reduction [23-25]. Fanwei [26] used dynamic programming algorithm to optimize the control of hydraulic hybrid vehicle, established the objective function of engine energy consumption, and obtained the optimal parameters of energy consumption of hydraulic hybrid engine by optimizing the objective function. Aishwarya [27] studied the minimum fuel consumption strategy of hydraulic hybrid power, and established the fuel consumption model of hydraulic hybrid power vehicles. Sebastien [28] studied the optimal fuel control strategy for hydraulic hybrid vehicles based on the optimal control theory, and improved fuel economy through simulation and analysis of the optimal control effect.

Hydraulic hybrid power is a new type of power system based on secondary regulation hydrostatic transmission technology, the hydraulic hybrid power system can be divided into serial type and parallel type structures according to the connection between the main power source and the secondary components [29-30]. The comparison between the serial type and parallel type is shown in table 3 . It can be seen that the overall performance of the serial type hydraulic hybrid power system is superior to the parallel type. By combining and changing the two basic structures of serial and parallel, the mixed structure and wheel side driven structure can be obtained [31-32].

Table 3. Comparison of parallel and serial hydraulic hybrid control system.

\begin{tabular}{|c|c|c|c|c|c|}
\hline Type & Engine efficiency & $\begin{array}{l}\text { Kinetic energy } \\
\text { recovery efficiency }\end{array}$ & Energy conversion efficiency & Control performance & Weight \\
\hline Parallel & $\begin{array}{l}\text { The operation mode is almost } \\
\text { the same as traditional vehicles, } \\
\text { and the overall efficiency is } \\
\text { limited. }\end{array}$ & $\begin{array}{l}\text { Parallel and serial are the } \\
\text { same energy recovery } \\
\text { system, the recycling } \\
\text { efficiency is basically } \\
\text { the same. }\end{array}$ & $\begin{array}{l}\text { Mechanical transmission is still } \\
\text { needed, energy conversion } \\
\text { efficiency is low. }\end{array}$ & $\begin{array}{l}\text { The engine system and the } \\
\text { hydraulic system need to be } \\
\text { controlled separately, which } \\
\text { is more complicated. }\end{array}$ & Heavy \\
\hline Serial & $\begin{array}{l}\text { The vehicle engine is only used } \\
\text { as the power output to drive the } \\
\text { hydraulic pump, which has } \\
\text { higher efficiency. }\end{array}$ & $\begin{array}{l}\text { The hydraulic system } \\
\text { provides power output } \\
\text { for the vehicle, the } \\
\text { power is high. }\end{array}$ & $\begin{array}{l}\text { The energy conversion is } \\
\text { completed by hydraulic system, the } \\
\text { conversion efficiency is high. }\end{array}$ & $\begin{array}{l}\text { The hydraulic system is } \\
\text { connected with the vehicle } \\
\text { engine, the control is } \\
\text { relatively simple. }\end{array}$ & Light \\
\hline
\end{tabular}

\section{Conclusions}

1) The towbarless traction can make the aircraft and the tractor become a whole one, which can avoid the damage of the traction bar to the aircraft when the tractor is turning, starting and accelerating. At the same time, a part of the weight of the aircraft can be used to increase the traction force of the tractor and improve the traction capacity.

2) Hydraulic drive aircraft tractor has good traction, braking and control characteristics. It can easily adjust the relationship between traction force and vehicle speed. It can work for a long time under the condition of low speed and large traction force. The power transmission is soft, and the impact on the aircraft is small.

3) Electronic hydraulic braking control system is the development trend of hydraulic braking system, it has the advantages of fast response, accurate and controllable braking. Hydraulic hybrid technology can realize the quick and effective recovery and release of braking energy in a short time. The application of hydraulic hybrid power technology in aircraft towing tractor can reduce the energy consumption of the tractor and realize the energy saving and emission reduction.

4) Aircraft towing tractor will develop towards the direction of high efficiency, energy saving, emission reduction and intelligence to meet the needs of various airport conditions. With the expansion of airport construction scale, the demand for aircraft towing tractor will continue to increase. The development of aircraft towing tractor with high energy saving, low emission pollution and high intelligence is an important development direction in the future.

\section{References}

[1] YAN Min, ZHAO Lijun, JIANG Jihai, LIU Tai. Development of Structure and Power Transmission System in Aircraft Towing Tractor [J]. Chinese Hydraulics \& Pneumatics, 2009, (12): 1-4.

[2] Roth D, Jacobs G, Pietrzyk T, Schmitz K. Decentralized Compact Hydraulic Power Supply by High Speed Components [J]. ATZ heavy duty worldwide, 2019, 12 (1): 66-71.

[3] Weich C, Bayer D, Puckmayr D. Challenges of functional safety in tractor development [J]. ATZ offhighway worldwide, 2017, 10 (4): 56-59.

[4] Zhang R, Yu X, Hu Y. Zang H, Shu W. Active control of hydraulic oil contamination to extend the service life of aviation hydraulic system [J]. The International Journal of Advanced Manufacturing Technology, 2018, 96 (5-8): 1693-1704.

[5] Yang H, Pan M. Engineering research in fluid power: a review [J]. Journal of Zhejiang University-Science A, 2015, 16 (6): 427-442. 
[6] ZHU He, WANG Liwen, LUO Xinyue. Dynamics simulation analysis of air suspension towbarless towing vehicle [J]. Machine Tool \& Hydraulics, 2018, 46 (13): 144-147.

[7] LIU Chengxin, LIU Hui, SHENG Zhen. Simulation Analysis of Two Kinds of Aircraft Traction Control Based on ADAMS [J]. Industrial Control Computer, 2018, 31 (1): 77-81.

[8] Wang N, Liu H, Yang W. Path-tracking control of a tractor-aircraft system [J]. Journal of Marine Science and Application, 2012, 11 (4): 512-517.

[9] Alonso Tabares D, Mora-Camino F. Aircraft ground operations: steps towards automation [J]. CEAS Aeronautical Journal, 2019, 10 (3): 965-974.

[10] Hasan Y J, Sachs F, Dauer J C. Preliminary design study for a future unmanned cargo aircraft configuration [J]. CEAS Aeronautical Journal, 2018, 9 (4): 571-586.

[11] Egorova O A, Darsht Y A, Kuznetsova S V. Modeling of automatic control mechanism for the hydraulic transmission of a transportation robot under nonlinear motion characteristics [J]. Automation and Remote Control, 2018, 79 (4): 768-773.

[12] Hasan M E, Ghoshal S K, Dasgupta K, Kumar N. Dynamic analysis and estimator design of a hydraulic drive system [J]. Journal of the Brazilian Society of Mechanical Sciences and Engineering, 2017, 39 (4): 1097-1108.

[13] WANG Cuntang, FENG Yixian, FANG Yijun, JIAO Wenrui, XIE Fangwei. Design and experimental study of electronic control synchronous full hydraulic steering system [J]. Machine Tool \& Hydraulics, 2018, 46 (22): 30-40.

[14] ZHANG Yinghe, GUO Feng, YANG Shiqiang. Modeling and analysis based on AMESim full hydraulic steering system [J]. Journal of Mechanical \& Electrical Engineering, 2019, 36 (7): 690-694.

[15] YANG Xiaofei, YANG Ruining, LI Chonghao. Analyse and design of steering system on aircraft towing tractor [J]. Hydraulics Pneumatics \& Seals, 2017, (4): 5-7.

[16] Wachter E, Ngu TQ, Alirand M. Virtual simulation of an electro-hydraulic braking system [J]. ATZ worldwide, 2019, 121 (7-8): 54-59.

[17] YU Zhuoping, SHI Biaofei, XIONG Lu, HAN Wei, SHU Qiang. Coordinated control of hybrid braking based on integrated-electro-hydraulic brake system [J]. Journal of Tongji University (Natural Science), 2019, 47 (6): 851-856.

[18] WANG Liwen, WU Zhiheng, ZHANG Wei. Kinematics analysis for clamping and lifting mechanism of towbarless aircraft tractor [J]. Machine Tool \& Hydraulics, 2015, 43 (23): 54-57.

[19] Huang H, Zou X, Li L, Li X, Liu Z. Energy-saving design method for hydraulic press drive system with multi motor-pumps [J]. International Journal of Precision Engineering and Manufacturing-Green Technology, 2019, 6 (2): 223-234.

[20] Hettesheimer T, Hirzel S, Roß H B. Energy savings through additive manufacturing: an analysis of selective laser sintering for automotive and aircraft components [J]. Energy Efficiency, 2018, 11 (5): 1227-1245.

[21] DONG Han, LIU Xinhui, WANG Xin, ZHENG Boyuan, LIANG Weiquan, WANG Jiayi. Impact of main parameters of accumulator on parallel hydraulic hybrid [J]. Journal of Jilin University (Engineering and Technology Edition), 2015, 45 (2): 421-428.

[22] ZHAO Lijun, WANG Xin, JIANG Jihai. Study on brake control system of aircraft towing tractor base on hydraulic hybrid [J]. Journal of Harbin Institute of Technology, 2011, 43 (9): 81-85.

[23] Shen W, Wang J. Adaptive fuzzy sliding mode control based on pi-sigma fuzzy neutral network for hydraulic hybrid control system using new hydraulic transformer [J]. International Journal of Control, Automation and Systems, 2019, 17 (7): 1708-1716.

[24] Liu Y, Chen D, Lei Z, Qin D, Zhang Y, Wu R, Luo Y. Modeling and control of engine starting for a full hybrid electric vehicle based on system dynamic characteristics [J]. International Journal of Automotive Technology, 2017, 18 (5): 911-922.

[25] Comunian A, Giudici, M. Hybrid inversion method to estimate hydraulic transmissivity by combining multiple-point statistics and a direct inversion method [J]. Mathematical Geosciences, 2018, 50 (2): 147-167.

[26] FAN Wei, LIU Tianq. Simulation study on energy consumption of hydraulic hybrid vehicle optimized by dynamic programming algorithm [J]. Chinese Journal of Construction Machinery, 2018, 16 (6): 526-530.

[27] Aishwarya P, OM B H. Energy management strategy implementation for hybrid electric vehicles using genetic algorithm tuned pontryagin's minimum principle controller [J]. International Journal of Vehicular Technology, 2016, 20 (5): 301-315.

[28] Sebastien D, Theo H, Sebastien P. Hybrid vehicle energy management: singular optimal control [J]. IEEE Transactions on Vehicular Technology, 2017, 66 (11): 9654-9666.

[29] XU Lei, HE Xiaohui, WANG Qiang. Analysis of hydraulic hybrid vehicle driving / braking system and its control strategy [J]. Journal of Ordnance Equipment Engineering, 2018, 39 (2): 56-60.

[30] LIU Huiyong, XIONG Yeping, ZHAO Qing. Research status and development trends of hydraulic hybrid drive construction machinery [J]. Machine Tool \& Hydraulics, 2017, 45 (23): 167-171.

[31] WANG Xin, JIANG Jihai. Regenerative braking control strategy for wheel drive hydraulic hybrid vehicle [J]. Journal of Jilin University (Engineering and Technology Edition), 2009, 39 (6): 1544-1549.

[32] ZHANG Tao, HE Xiaohui, WANG Qiang, LI Sisheng. Research on energy recovery system of wheel drive hydraulic hybrid vehicle [J]. Chinese Hydraulics \& Pneumatics, 2019, (10): 90-96. 